\title{
The Effects of Ethanol Concentration and of Ionic Strength on the Zeta Potential of Titania in the Presence of Sodium Octadecyl Sulfate
}

\author{
Marek Kosmulski * (D) and Edward Mączka \\ Laboratory of Electrochemistry, Lublin University of Technology, ul. Nadbystrzycka 38, 20618 Lublin, Poland; \\ e.maczka@pollub.pl \\ * Correspondence: m.kosmulski@pollub.pl
}

Received: 21 September 2020; Accepted: 26 October 2020; Published: 2 November 2020

\begin{abstract}
Sodium octadecyl sulfate $\left(\mathrm{C}_{18} \mathrm{H}_{37} \mathrm{SO}_{4} \mathrm{Na}\right)$ induces a negative zeta potential of metal oxides at very low surfactant concentrations as compared with shorter-chained sodium alkyl sulfates. The problem of low solubility of sodium octadecyl sulfate in water was solved by the addition of the surfactant to dispersions as ethanolic stock solution, but then the presence of ethanol in dispersions was inevitable. We demonstrate that the concentration of ethanol (up to $5 \%$ by mass) in a dispersion containing titania $\left(\mathrm{TiO}_{2}\right)$ and sodium octadecyl sulfate has an insignificant effect on the zeta potential of particles. We further demonstrate that the shifts in the IEP of titania induced by the presence of sodium octadecyl sulfate are independent of the $\mathrm{NaCl}$ concentration. The results obtained in this study can be generalized for 1-1 salts other than $\mathrm{NaCl}$, for metal oxides other than titania, for organic co-solvents other than ethanol, and for sparingly soluble ionic surfactants other than sodium octadecyl sulfate.
\end{abstract}

Keywords: isoelectric point; anionic surfactant; anatase; mixed solvent; electrophoretic mobility; pH-dependent surface charging; solubility

\section{Introduction}

Ionic surfactants induce substantial shifts in the isoelectric point (IEP) of solid particles even at very low concentrations, and long-chained surfactants and more efficient in this respect than their shorter-chained analogs [1,2]. Anionic surfactants shift the IEP to low $\mathrm{pH}$, and cationic surfactants shift the IEP to high $\mathrm{pH}$, and at sufficiently high surfactant concentration, the zeta potentials are negative over the entire $\mathrm{pH}$ range for anionic surfactants [3,4], and positive over the entire $\mathrm{pH}$ range for cationic surfactants $[5,6]$. On top of the shifts in the IEP induced by surfactants alone, dispersions containing surfactants and other compounds, e.g., polymers [7,8], sugars [9-11], and mixtures of various surfactants [12] have been extensively studied. The shifts in the IEP observed in such dispersions are not necessarily simple sums of the effects of particular solutes, but they may show unexpected synergistic or competitive effects. Such effects are due to the interactions between the solutes in bulk solution and on the surface. As this work appears in a Special Issue, we emphasize that Professor Emil Chibowski published a substantial number of papers devoted to the adsorption of surfactants from solution [13-15], although his work is not directly related to this study.

The low solubility of long-chained surfactants in water is a problem which reduces their applications, and most published studies have been carried out with water-soluble surfactants. We showed, in our recent paper [16], that dilute aqueous solutions of surfactants which are sparingly soluble in water can be conveniently prepared from their stock solutions in water-miscible organic solvents. In particular, sodium octadecyl sulfate shows sufficient solubility in ethanol to prepare its aqueous 
solutions (up to saturation and even supersaturated) by dilution of ethanolic stock solution. We used sodium octadecyl sulfate to shift the IEP of alumina, titania and hematite to low $\mathrm{pH}$ and to induce negative zeta potential of these oxides over the entire $\mathrm{pH}$ range. Since we added the surfactant to the dispersions as ethanolic solution, we have to consider if ethanol (which was inevitably present in the dispersion) could have affected the adsorption behavior of the surfactant, and consequently the zeta potential of oxide particles. We originally assumed that in view of the low concentration of ethanol (less than $1 \%$ by mass in most dispersions, ethanol concentration was variable and proportional to the concentration of surfactant) and thus negligible effect of ethanol on the physical properties of the mixed solvent, the effect of the organic co-solvent on the adsorption of sodium octadecyl sulfate is also negligible. It is also very unlikely that an amount of ethanol as low as a fraction of $1 \%$ would substantially affect the solubility of sodium octadecyl sulfate in water. Moreover, there is direct experimental evidence that ethanol (up to $30 \%$ ) does not affect the zeta potential of oxide particles when the ionic strength is not too high (below 0.1 M) [17]. Yet, a negligible effect of alcohol on the zeta potential in metal oxide dispersions containing sodium octadecyl sulfate needs a direct experimental evidence, and this is the goal of the present study. In order to prove that ethanol indeed does not affect the zeta potentials in the above systems, we compare the results obtained in dispersions containing less than $1 \%$ of ethanol [16] with similar dispersions except containing $5 \%$ ethanol. If the difference in the zeta potential between dispersions containing $<1 \%$ on the one hand and $5 \%$ ethanol on the other is negligible, then we can safely assume that also the difference between dispersions containing 0 and up to $5 \%$ ethanol is negligible. The concentration of ethanol (5\% by mass) used in this study was arbitrarily selected as a compromise between two opposite requirements. The concentration must be higher by at least a factor of two than the highest concentration used in our previous study (only comparison of results obtained at substantially different concentrations of ethanol can potentially produce significantly different zeta potentials). On the other hand, high concentrations of ethanol cause a number of difficulties, e.g., with definition and measurements of $\mathrm{pH}$, with incomplete dissociation of the electrolyte, etc. These problems were discussed in detail in our previous studies [18].

Five $\%$ ethanol solution has higher viscosity and lower dielectric constant that water, and these quantities affect the calculation of the zeta potential from electrophoretic mobility, but the physical constants for water-ethanol mixtures are easily available from the literature [19]. Moreover, we studied the effect of the ionic strength on the zeta potential in metal oxide dispersions containing sodium octadecyl sulfate. Published literature [3] and our previous experiments showed that the increase in $\mathrm{NaCl}$ concentration from $10^{-3}$ to $10^{-2} \mathrm{M}$ had a rather insignificant effect on the shifts in the IEP caused by SDS.

The range of the ionic strengths discussed in this paper and in other similar studies is limited by the following factors:

- With very low ionic strengths $\left(10^{-4} \mathrm{M}\right.$ or less), the available $\mathrm{pH}$ range is limited. For example, with the ionic strength of $10^{-4} \mathrm{M}$, a pH below 4 is not available, because at $\mathrm{pH}<4$ the acid added to adjust the $\mathrm{pH}$ produces an ionic strength higher than $10^{-4} \mathrm{M}$. In other words, a very low ionic strength is difficult to adjust and control.

- With very high ionic strengths $\left(10^{-1} \mathrm{M}\right.$ or more) the dispersions are unstable against coagulation, especially near the IEP, while electrophoretic measurements require a relatively stable dispersion. Moreover, the zeta potentials at high ionic strengths are low in absolute value, and the signal-to-noise ratio is poor. This problem can be solved by using the electroacoustic technique [20] instead of electrophoresis, but this is a separate topic unrelated to the present work.

We may generalize the above findings with SDS for other sodium alkyl sulfates, but again, direct experimental proof would be much desired. For example, $\mathrm{NaCl}$, even at low concentrations, can affect the solubility of sodium octadecyl sulfate, and thus, indirectly, its adsorption. In order to directly answer the question about the possible effect of the ionic strength we compare the zeta potentials of titania in the presence of sodium octadecyl sulfate obtained in $10^{-3}$ and $10^{-2} \mathrm{M} \mathrm{NaCl}$ at otherwise the 
same conditions. Titanium dioxide is not only a perfect model system in the studies of $\mathrm{pH}$-dependent surface charging (low solubility, point of zero charge PZC in the center of the pH-scale), but it also has wide applications, e.g., as the component of paints, cosmetics, paper whitener, and even food additive, thus the results showed in this study may be directly applied in practice.

\section{Materials and Methods}

A series of 1:10,000 w/w dispersions of P25 (Evonik, Essen, Germany), which is $\mathrm{TiO}_{2}$, chiefly anatase, was prepared by mixing titania powder with ethanolic solution of sodium octadecyl sulfate, $98 \%$ (Acros, Geel, Belgium), 96\% ethanol (Stanlab, Lublin, Poland), $0.1 \mathrm{M} \mathrm{NaCl}$ (POCh, Lublin, Poland) and water (Hydrolab, Straszyn, Poland) in different proportions to obtain desired concentrations of the surfactant, of ethanol, and of $\mathrm{NaCl}$. The dispersions were adjusted to different $\mathrm{pH}$ using $\mathrm{NaOH}$ and $\mathrm{HCl}$ solutions. The dispersions were stored in plastic test tubes and used shortly after preparation.

The electrophoretic mobility was studied with a Malvern ZetaSizer Nano ZS (Malvern, Malvern, England) at $25^{\circ} \mathrm{C}$, and the Smoluchowski equation was used to calculate the zeta potential. The viscosity and dielectric constant of $5 \%$ ethanol were taken directly or interpolated from the literature data. More detailed description of the experimental procedures can be found elsewhere [16].

\section{Results and Discussion}

The zeta potential vs. $\mathrm{pH}$ curves of titania obtained at a few selected concentrations of sodium octadecyl sulfate in $10^{-3}$ and $10^{-2} \mathrm{M} \mathrm{NaCl}$ in $5 \% w / w$ ethanol are presented in Figures 1 and 2, respectively. We must emphasize that all surfactant concentrations reported in this paper are total (rather than equilibrium) concentrations. The sets of electrokinetic curves obtained at different surfactant concentrations shown in Figures 1 and 2 are very similar, and they are also similar to analogous results from our previous study [16], obtained at a lower concentration of ethanol (variable, up to $0.7 \%$ w/w). They show the following common behavior, which is independent of alcohol concentration and of the ionic strength:

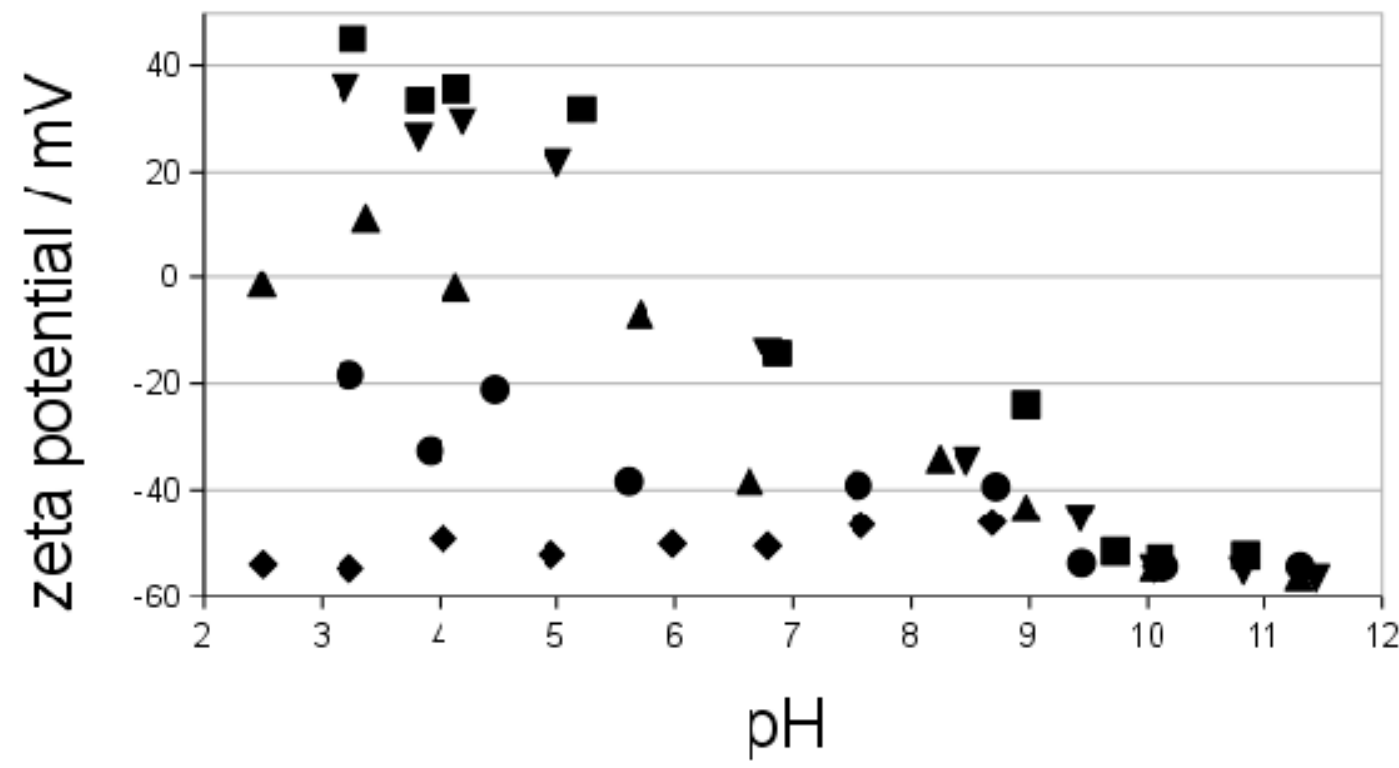

Figure 1. The zeta potentials of titania in $10^{-3} \mathrm{M} \mathrm{NaCl}$ at various concentrations of sodium octadecyl sulfate in $5 \%$ ethanol. $\mathbf{\square} 0, \mathbf{\nabla} 1.1 \times 10^{-6}, \mathbf{\Delta} 5.4 \times 10^{-6}, \bullet 1.1 \times 10^{-5}, \bullet 2.1 \times 10^{-5}$ M sodium octadecyl sulfate. 


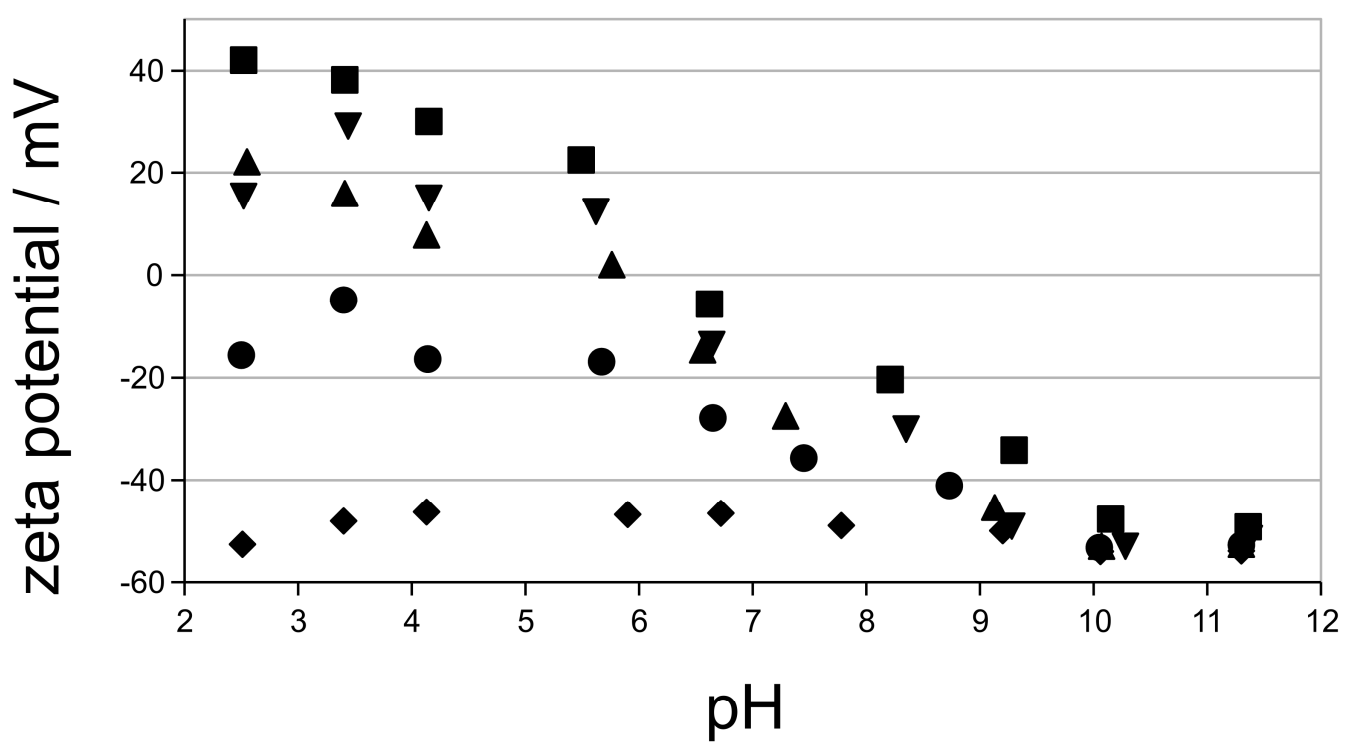

Figure 2. The zeta potentials of titania in $10^{-2} \mathrm{M} \mathrm{NaCl}$ at various concentrations of sodium octadecyl sulfate in $5 \%$ ethanol. $\mathbf{\square} 0, \mathbf{\nabla} 3.2 \times 10^{-6}, \mathbf{\Lambda} 5.4 \times 10^{-6}, \bullet 1.1 \times 10^{-5}, 2.1 \times 10^{-5}$ M sodium octadecyl sulfate.

- IEP at pH 6.5 in the absence of surfactant and at very low surfactant concentrations, which is consistent with IEP of P25 and of other titanias reported in the literature [21].

- Substantial shift in the IEP at $5.4 \times 10^{-6} \mathrm{M}$ sodium octadecyl sulfate, but still positive zeta potentials in the acidic range.

- Negative zeta potentials over the entire $\mathrm{pH}$-range at $1.1 \times 10^{-5} \mathrm{M}$ sodium octadecyl sulfate, but the zeta potentials are more negative (about $-50 \mathrm{mV}$ ) at $\mathrm{pH}>7$, and less negative (about $-20 \mathrm{mV}$ ) at $\mathrm{pH}<4$.

- Negative and $\mathrm{pH}$-independent zeta potentials of about $-50 \mathrm{mV}$ over the entire $\mathrm{pH}$-range at $2.1 \times 10^{-5}$ M sodium octadecyl sulfate.

The above numerical values of surfactant concentrations refer to specific solid-to-liquid ratio (1:10,000 in our study) and they will be different if we change this ratio. Normalization of "critical" surfactant concentrations to amount of surfactant per unit of specific surface area (rather than to concentration in solution) in comparison of results obtained at various solid-to-liquid ratios has been considered [3,6], but even the normalized "critical" concentrations are not entirely consistent.

The results from our previous study (low concentration of ethanol) [16] and from the present study (5\% ethanol), Figure $1\left(10^{-3} \mathrm{M} \mathrm{NaCl}\right)$ and Figure $2\left(10^{-2} \mathrm{M} \mathrm{NaCl}\right)$, are compared in Figure 3 . In order to avoid overcrowding of data points, we plot the zeta potential at constant $\mathrm{pH}(3$ or 4$)$ as the function of surfactant concentration at various concentrations of $\mathrm{NaCl}$ and of ethanol. The similarity of zeta potentials in nearly alcohol-free dispersions (squares) on the one hand, and in dispersions in $5 \%$ ethanol (circles) on the other, suggests that, at least over the concentration range of $0-5 \%$, ethanol does not affect the zeta potential in dispersions of titania containing sodium octadecyl sulfate.

The zeta potential vs. $\mathrm{pH}$ curves of titania obtained at different concentrations of sodium octadecyl sulfate in $10^{-3} \mathrm{M} \mathrm{NaCl}$ in $5 \% w / w$ ethanol (circles) are very similar to analogous results obtained with $10^{-2} \mathrm{M} \mathrm{NaCl}$ (triangles). This result shows that $\mathrm{NaCl}$ does not affect the shifts in the IEP and the sign reversal of the zeta potential from positive to negative in the acidic range induced by sodium octadecyl sulfate. 
$\mathrm{pH} 3$

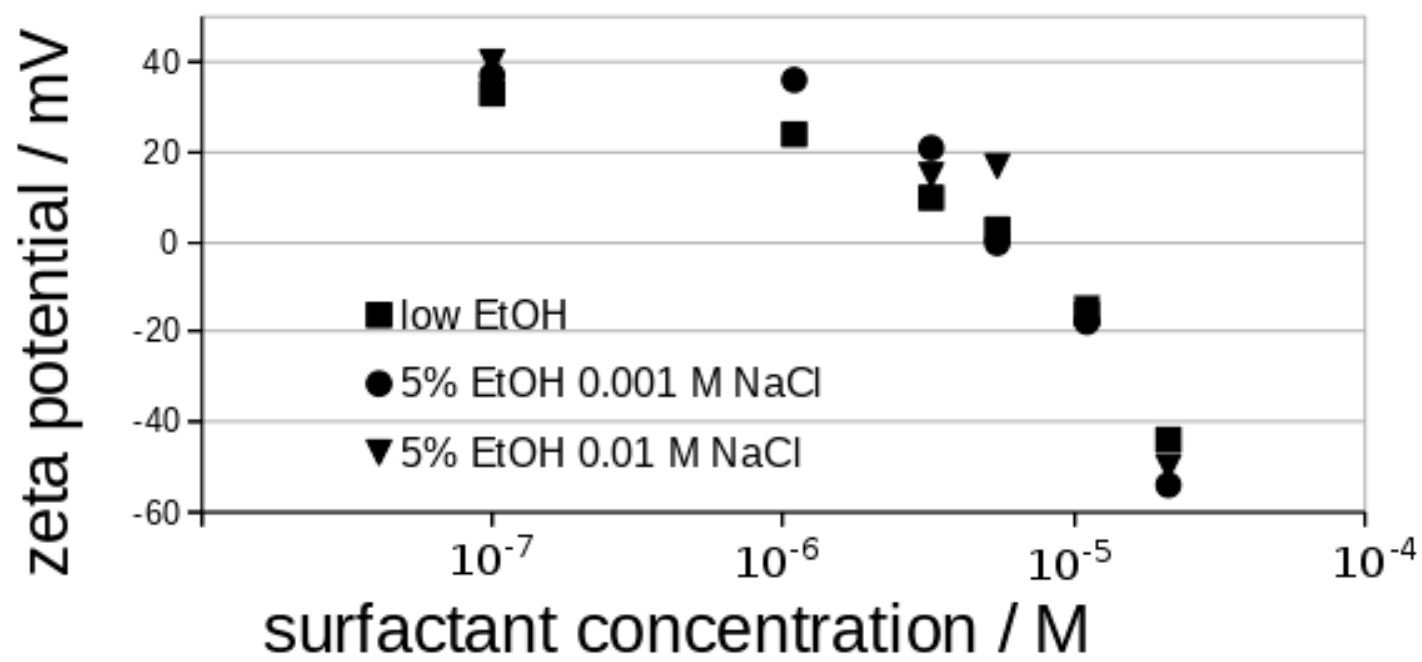

(a)

$\mathrm{pH} 4$

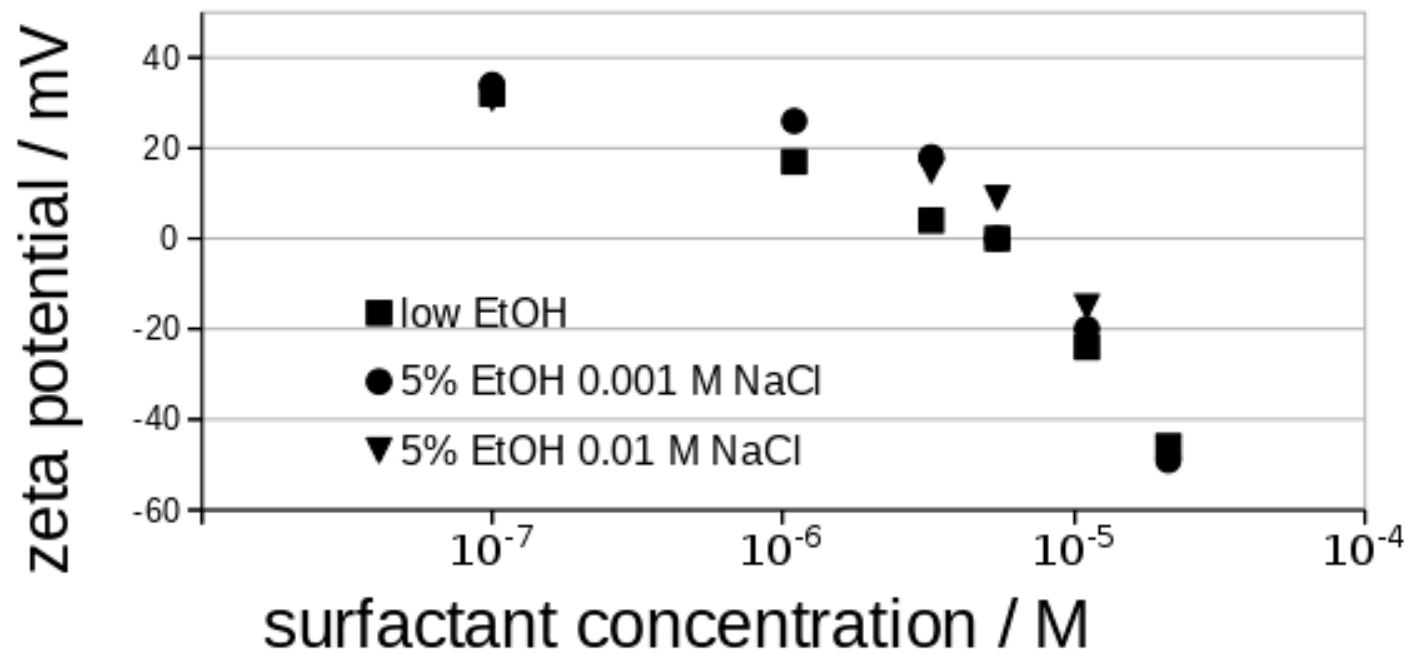

(b)

Figure 3. The zeta potentials of titania at $\mathrm{pH} 3$ (a) and 4 (b) interpolated from the results shown in Figures 1 and 2 at various concentrations of $\mathrm{NaCl}$ and of ethanol.

We only performed experiments in a carefully selected model system: for one metal oxide (titania), one salt $(\mathrm{NaCl})$, one ionic surfactant (sodium octadecyl sulfate) and one organic co-solvent (ethanol). The results presented in this study corroborate the expectations, and they can probably be generalized. Due to the similarity of surface-charging behavior of different metal oxides in solutions of different 1-1 electrolytes, we suppose that insensitivity of electrokinetic curves presented in Figure 3 to the concentration of ethanol (at least up to $5 \%$ ) and to the concentration of $\mathrm{NaCl}$ (at least up to $10^{-2} \mathrm{M}$ ) can be generalized for other metal oxides (hematite, alumina, zirconia), and for other 1-1 salts $\left(\mathrm{KCl}, \mathrm{KNO}_{3}\right.$, $\mathrm{NaClO}_{4}$ ). We further speculate that our present results are also valid for other polar organic co-solvents 
(acetone, acetonitrile), and even for other long-chained ionic surfactants. In other words, our study further confirms that the shifts in the IEP of metal oxides induced by ionic surfactants and rather insensitive to the nature and concentration (at least up to $10^{-2} \mathrm{M}$ ) of 1-1 salt present in the dispersion irrespective of the nature of the metal oxide, of organic co-solvent, and of the surfactant. Our results suggest that also addition of water-miscible organic co-solvent (at least up to $5 \% w / w$ ) does not affect the shifts in the IEP of metal oxides induced by ionic surfactants. The later conclusion is new, and we have not found similar experimental studies in the literature. Many electrokinetic studies have been carried out with solutions of surfactants in anhydrous or nearly anhydrous organic solvents [22,23], but this is a completely different topic unrelated to the present work.

The reversal of sign of the zeta potential of quartz to positive at $\mathrm{pH}$ 6.5-6.9 induced by long chained amine acetates (up to C18) was studied in [24]. Unlike in the present study, the cationic surfactants studied in [24] have sufficient solubility in water to reverse the sign of the zeta potential of quartz within the solubility limit. The IEPs reported in [24] are not comparable with the IEPs presented in Figure 3 of this study, because quartz has a low specific surface area.

Our previous study [2] showed two types of sets of zeta potential vs. $\mathrm{pH}$ curves obtained at moderate anionic surfactant concentrations. A maximum in zeta potential vs. $\mathrm{pH}$ curves at $\mathrm{pH}$ near the pristine IEP of the powder was observed in shorter-chained surfactants, but not in their longer-chained analogs. Most examples in [2] were sodium alkyl sulfates. One of the referees of this papers turned our attention to [25], where a sharp maximum in the zeta potential of alumina at $\mathrm{pH} 6.9$ in the presence of sodium dodecyl sulfonate was reported. Unlike most studies cited in Reference [2], in which the zeta potential was studied at constant total surfactant concentration, the graph in Reference [25] was obtained at a constant residual surfactant concentration.

Author Contributions: M.K.: conceptualization, writing; E.M.: experiment. All authors have read and agreed to the published version of the manuscript.

Funding: This research received no external funding.

Conflicts of Interest: The authors declare no conflict of interest.

\section{References}

1. Fuerstenau, D.W.; Colic, M. Self-association and reverse hemimicelle formation at solid-Water interfaces in dilute surfactant solutions. Colloids Surf. A 1999, 146, 33-47. [CrossRef]

2. Kosmulski, M.; Maczka, E.; Ruchomski, L. Two types of electrokinetic behavior of solid particles in the presence of anionic surfactants. J. Colloid Interf. Sci. 2019, 533, 34-41. [CrossRef] [PubMed]

3. Kobayashi, M.; Yuki, S.; Adachi, Y. Effect of anionic surfactants on the stability ratio and electrophoretic mobility of colloidal hematite particles. Colloids Surf. A 2016, 510, 190-197. [CrossRef]

4. Colic, M.; Fuerstenau, D.W. The influence of surfactant impurities on colloid stability and dispersion of powders in aqueous suspensions. Powder Technol. 1998, 97, 129-138. [CrossRef]

5. Szekeres, M.; Dekany, I.; de Keizer, A. Adsorption of dodecyl pyridinium chloride on monodisperse porous silica. Colloids Surf. A 1998, 141, 327-336. [CrossRef]

6. Mączka, E.; Luetzenkirchen, J.; Kosmulski, M. The significance of the solid-to-liquid ratio in the electrokinetic studies of the effect of ionic surfactants on mineral oxides. J. Colloid Interf. Sci. 2013, 393, 228-233. [CrossRef] [PubMed]

7. Wisniewska, M.; Chibowski, S.; Urban, T. Nanozirconia surface modification by anionic polyacrylamide in relation to the solid suspension stability-Effect of anionic surfactant addition. Powder Technol. 2016, 302, 357-362. [CrossRef]

8. Chibowski, S.; Paszkiewicz, M.; Patkowski, J. Adsorption of poly(acrylic acid) on the surface of $\mathrm{TiO}_{2}$ in the presence of different surfactants. Physicochem. Probl. Miner. Process 2012, 48, 317-324.

9. Grzadka, E. Competitive adsorption in the system: Carboxymethylcellulose/surfactant/electrolyte/ $\mathrm{Al}_{2} \mathrm{O}_{3}$. Cellulose 2011, 18, 291-308. [CrossRef]

10. Matusiak, J.; Grzadka, E.; Bastrzyk, A. Stability, adsorption and electrokinetic properties of the chitosan/silica system. Colloids Surf. A 2018, 554, 245-252. [CrossRef] 
11. Grzadka, E. Study on the influence of surfactants on the adsorption and electrokinetic properties of the system: Cationic starch/alumina. Fluid Phase Equil. 2015, 401, 48-55. [CrossRef]

12. Colic, M.; Fisher, M.L.; Fuerstenau, D.W. Electrophoretic behaviour and viscosities of metal oxides in mixed surfactant systems. Colloid Polym. Sci. 1998, 276, 72-80. [CrossRef]

13. Chibowski, E.; Holysz, L.; Terpilowski, K. Influence of ionic surfactants and lecithin on stability of titanium dioxide in aqueous electrolyte solution. Croat. Chem. Acta 2007, 80, 395-403.

14. Chibowski, E.; Szczes, A.; Holysz, L. Influence of sodium dodecyl sulfate and static magnetic field on the properties of freshly precipitated calcium carbonate. Langmuir 2005, 21, 8114-8122. [CrossRef] [PubMed]

15. Yezek, L.; Rowell, R.L.; Holysz, L.; Chibowski, E. Adsorption of sodium dodecyl sulfate to colloidal titanium dioxide: An electrophoretic fingerprinting investigation. J. Colloid Interf. Sci. 2000, 225, 227-232. [CrossRef] [PubMed]

16. Kosmulski, M.; Maczka, E.; Ruchomski, L. The effect of sodium octadecyl sulfate on the electrokinetic potential of metal oxides. Colloids Surf. A 2020, 605, 125353. [CrossRef]

17. Kosmulski, M.; Matijevic, E. Zeta potential of anatase $\left(\mathrm{TiO}_{2}\right)$ in mixed solvents. Colloids Surf. 1992, 64, 57-65. [CrossRef]

18. Kosmulski, M.; Matijevic, E. Zeta-potentials of silica in water alcohol mixtures. Langmuir 1992, 8, 1060-1064. [CrossRef]

19. Wyman, J. The dielectric constant of mixtures of ethyl alcohol and water from -5 to $40^{\circ}$. J. Am. Chem. Soc. 1931, 53, 3292-3301. [CrossRef]

20. Kosmulski, M.; Rosenholm, J.B. High ionic strength electrokinetics. Adv. Colloid Interf. Sci. 2004, 112, 93-107. [CrossRef]

21. Kosmulski, M. Isoelectric points and points of zero charge of metal (hydr)oxides: 50 years after Parks' review. Adv. Colloid Interf. Sci. 2016, 238, 1-61. [CrossRef]

22. Poovarodom, S.; Berg, J.C. Effect of particle and surfactant acid-base properties on charging of colloids in apolar media. J. Colloid Interf. Sci. 2010, 346, 370-377. [CrossRef] [PubMed]

23. Gacek, M.M.; Berg, J.C. The role of acid-base effects on particle charging in apolar media. Adv. Colloid Interf. Sci. 2015, 220, 108-123. [CrossRef] [PubMed]

24. Somasundaran, P.; Fuerstenau, D.W.; Healy, T.W. Surfactant adsorption at solid-liquid interface-dependence of mechanism on chain length. J. Phys. Chem. 1964, 68, 3562. [CrossRef]

25. Somasundaran, P.; Fuerstenau, D.W. Mechanisms of alkyl sulfonate adsorption at alumina-water interface. J. Phys. Chem. 1966, 70, 90. [CrossRef]

Publisher's Note: MDPI stays neutral with regard to jurisdictional claims in published maps and institutional affiliations.

(C) 2020 by the authors. Licensee MDPI, Basel, Switzerland. This article is an open access article distributed under the terms and conditions of the Creative Commons Attribution (CC BY) license (http://creativecommons.org/licenses/by/4.0/). 